\section{From chemical neuroanatomy to an understanding of the olfactory system}

\author{
L. Oboti, P. Peretto, S. De Marchis, \\ A. Fasolo \\ Department of Animal and Human \\ Biology, University of Turin, Italy
}

\begin{abstract}
The olfactory system of mammals is the appropriate model for studying several aspects of neuronal physiology spanning from the developmental stage to neural network remodelling in the adult brain. Both the morphological and physiological understanding of this system were strongly supported by classical histochemistry. It is emblematic the case of the Olfactory Marker Protein (OMP) staining, the first, powerful marker for fully differentiated olfactory receptor neurons and a key tool to investigate the dynamic relations between peripheral sensory epithelia and central relay regions given its presence within olfactory fibers reaching the olfactory bulb (OB). Similarly, the use of thymidine analogues was able to show neurogenesis in an adult mammalian brain far before modern virus labelling and lipophilic tracers based methods. Nowadays, a wealth of new histochemical techniques combining cell and molecular biology approaches is available, giving stance to move from the analysis of the chemically identified circuitries to functional research. The study of adult neurogenesis is indeed one of the best explanatory examples of this statement. After defining the cell types involved and the basic physiology of this phenomenon in the $\mathrm{OB}$ plasticity, we can now analyze the role of neurogenesis in well testable behaviours related to socio-chemical communication in rodents.
\end{abstract}

\section{Introduction}

Studying the rodent olfactory system yields important insights on different pivotal neural processes, such as: i) the development of neuro-endocrine circuits, through its early contribution of neuronal components migrating from the olfactory placode to the central nervous system (CNS), the best known of them being GnRH-1 neurons; ${ }^{1}$ ii) neural network modelling, based on the highly organized fine anatomy of the olfactory bulb (OB), whose columnar organization resembles an array of parallel computing devices; ${ }^{2}$ iii) the correlation between synaptic plasticity and learning capa- bilities in meaningful behavioural contexts; ${ }^{3-5}$ iv) plasticity and repair, including adult neurogenesis. ${ }^{6-11}$ Concerning the issue of neural plasticity, it is known that the olfactory system, both in the periphery (olfactory receptor neurons, ORNs) and in the $\mathrm{OB}$, is a major site of adult neurogenesis and neuronal turnover.,12 The ORNs are renewed by sensory neuron precursors residing in the basal laminae of the olfactory epithelia. Once mature, these neurons send axonal processes ensheathed by glial cells, which allow them to enter the mature CNS, in correspondence of $\mathrm{OB}$ glomeruli. ${ }^{13-15}$ Thus, persistent neurogenesis in the olfactory mucosa implies continuous remodelling of neural connections into the $\mathrm{OB}$ glomeruli. In parallel, the $\mathrm{OB}$ is the brain region most extensively enriched by new neurons throughout life. ${ }^{9}$ Here, inhibitory interneurons are constantly replaced by immature precursors whose lineage can be traced back to neural stem cells residing into the forebrain subventricular zone (SVZ). Produced by adult neural stem-cell mostly located at the periventricular level, these immature neurons follow a tangential migratory route (rostral migratory stream, RMS) to reach the $\mathrm{OB}$.

Importantly, the key advances in understanding the structure and functionality of this system have been strongly supported by histochemistry. Though classical histochemistry was pivotal in developing our ideas about olfactory system dynamics, at present a panoply of new powerful enabling techniques is available, and the monographic issue ${ }^{16}$ of Frontiers in Neurogenesis on Cellular Imaging and Emerging Technologies for Adult Neurogenesis Research gives relevant insights about up-todate technical and heuristic venues.

\section{Continuous renewal of olfactory receptor neurons}

ORNs contribute to form a relatively simple structure, the olfactory neuroepithelium, together with undifferentiated basal cells and non-neuronal supporting cells. Across the layers of the neuroepithelium there are cells at different stages of differentiation. Although the fully mature ORNs do retain juvenile characteristics, ${ }^{17}$ hall-marks for these cells are presently considered the adhesion molecule $\mathrm{N}$ CAM and a highly phylogenetically conserved protein of still unclear function, called olfactory marker protein (OMP) ${ }^{18,19}$ (Figure 1). Another molecule highly expressed in ORNs since early developmental stages is carnosine (Figure 2), an histidine-containing dipeptide particularly abundant in muscle and nervous tissue, whose biological functions in the CNS remain enigmatic ${ }^{20}$ although in the past it has
Correspondence: Prof. Aldo Fasolo, Department of Animal and Human Biology, University of Turin, via Accademia Albertina 13, 10123 Turin, Italy. Tel. +39.011 .6704642 - Fax: +39.011 .2364642$ E-mail: aldo.fasolo@unito.it

Key words: olfactory system, adult neurogenesis, immunohistochemistry, accessory olfactory bulb, vomeronasal system, structural plasticity.

Acknowledgments: this work was supported by Compagnia di San Paolo, Torino, MIUR. The authors wish to thank Claudio Gendusa for technical assistance, Adam C. Puche and Stefano Biffo for providing OMP and carnosine pictures.

This paper was presented by Prof. Aldo Fasolo at the XXXIV National Congress of the Italian Society of Histochemistry, San Benedetto del Tronto, Italy, June 7-9, 2011, as the Maffo Vialli Lecture, while receiving the Maffo Vialli International Award for Histochemistry.

Received for publication: 24 August 2011. Accepted for publication: 20 September 2011.

This work is licensed under a Creative Commons Attribution NonCommercial 3.0 License (CC BYNC 3.0).

(C) Copyright L. Oboti et al., 2011

Licensee PAGEPress, Italy

European Journal of Histochemistry 2011; 55:e35 doi:10.4081/ejh.2011.e35

been suggested to play a role as a neurotransmitter/modulator in olfaction. ${ }^{21}$

Olfactory sensory neurons are replaced under physiological conditions both in the olfactory mucosa ${ }^{22}$ and in the vomeronasal organ (VNO), ${ }^{23}$ with an average life-span ranging from 30 to 120 days. This property, which is enhanced after axotomy, bulbectomy or reversible lesion to the mucosa (Figure 3$)^{24,25}$ has been related to the fact that they are the only neurons that make direct physical contact with the environment. Importantly, this renewal process has been hypothesized to meet the functional requirements of particular olfactory sensory tasks. ${ }^{26}$ Although this is not the only example of adult neurogenesis (see below for neurogenesis in the adult CNS), ORNs remain an excellent and accessible model to study basic molecular and cellular events of adult neurogenesis. The saga of olfactory neurons grew towards legend with the elucidation of the nature of olfactory molecular receptors (OR) and the advent of all the elegant tricks revealing several receptor-ligand molecular interplays. Similarly important was the definition of the one receptor/one neuron role, achieved by targeted gene-expression analysis of olfactory receptors both on the epithelial as well as on the bulbar side. ${ }^{27}$

In fact, with the coming of genetic fluores- 
cent labelling, ${ }^{28,29}$ it became possible to identify a particular glomerulus by the type of $\mathrm{OR}$ expressed in the axons projecting to it by coexpression of $\tau \mathrm{GFP}$ with the OR protein, making the fluorescence evident in the glomeruli when they are formed.

\section{Adult structural plasticity and neurogenesis}

Up to the last two decades, a large gap still existing between developmental and adult mammalian structural plasticity, the term neurogenesis was used under its original, strictly embryological meaning, that is genesis of the nervous system, ${ }^{30}$ and not under the meaning of genesis

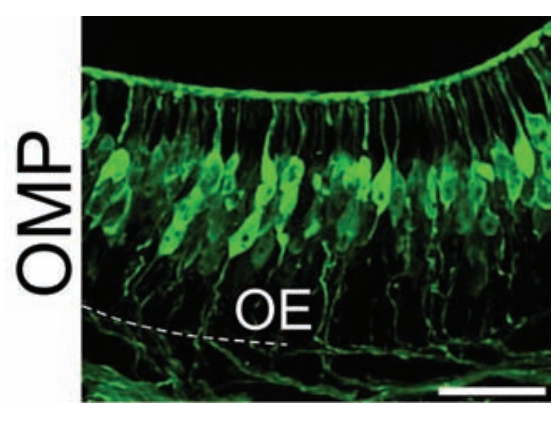

Figure 1. Olfactory epithelium (OE) stained with Olfactory Marker Protein (OMP), a marker for mature receptor neurons. Scale bar: $20 \mu \mathrm{m}$. Photography by Adam C. Puche (www.apuche.org/OIA/), copyright Adam C. Puche (reproduction authorized by the author).

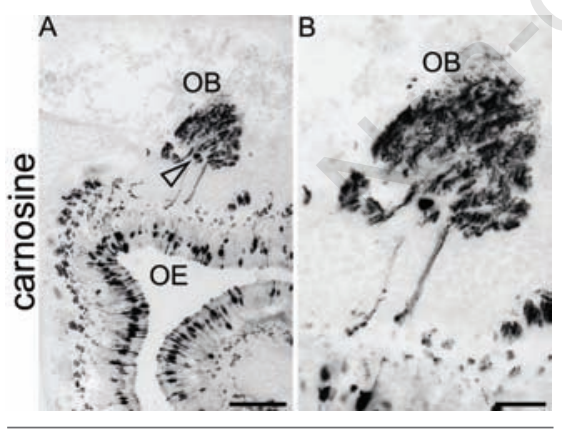

Figure 2. Carnosine staining in the olfactory pit during development (E15 mouse). A) At this stage, carnosine besides strongly labelling cell bodies and axonal projections of mature ORNs, is associated to a population of cells (arrowhead) migrating from the olfactory placode to the presumptive olfactory bulb (OB, olfactory bulb; $\mathrm{OE}$, olfactory epithelium). Scale bar: $55 \mu \mathrm{m}$. B) Higher magnification detail of the previous image showing a carnosine-positive migrating cell entering the rostral tip of the $O B$ within a bulk of carnosine-positive ORNs axons. Scale bar: $20 \mu \mathrm{m}$. of neurons, since it was universally admitted that no new neurons could be generated after the accomplishment of development. In the 70's, although during the previous decade some proliferative activity was firstly detected in the brain by using tritiated thymidine DNA incorporation as a marker of cell division, ${ }^{31,32}$ the issue of adult neurogenesis was sceptically envisaged. Nonetheless, in the subsequent years, comparative studies in vertebrates demonstrated interesting phenomena of adult neurogenesis primarily in non-mammalian species, such as songbirds, ${ }^{33,34}$ leading to the assumption that striking structural plasticity might be restricted to certain animal classes. ${ }^{5}$

A profound change in this vision occurred in the first 90 's, starting from two virtually simulta- neous findings: the occurrence of a massive cell migration toward the adult mammalian $\mathrm{OB}$, involving neuroblasts continuously-generated into the SVZ (Figure 4A), ${ }^{36,37}$ and the first isolation of adult neural stem cells. ${ }^{38}$ This conceptual and experimental revolution permitted to enhance former observations and to see the danger of erroneous prejudices. In addition, another marker, the polysialylated-NCAM was instrumental in order to identify migrating neuroblasts and their relations with the surrounding tissue and the scaffolding glial tubes. ${ }^{39,40}$ Nowadays, 5-bromo-2'-deoxyuridine (BrdU) is commonly used as thymidine analog to label proliferating cells and precisely birthdate newborn neurons using simple immunohistochemical protocols (Figure 4B).

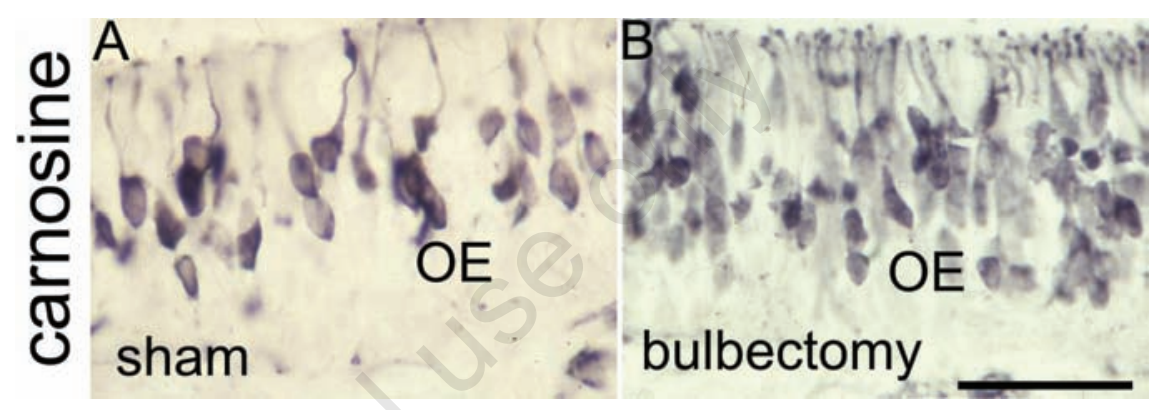

Figure 3. Carnosine staining in the adult rat main olfactory epithelium in control (A, left panel) and after bulbectomy ( $B$, right panel). The labelling shows the recovery of sensory neurons 35 days after bulbectomy: more cells populate the epithelia after lesion (right panel). Scale bar: $20 \mu \mathrm{m}$. Courtesy of Stefano Biffo.
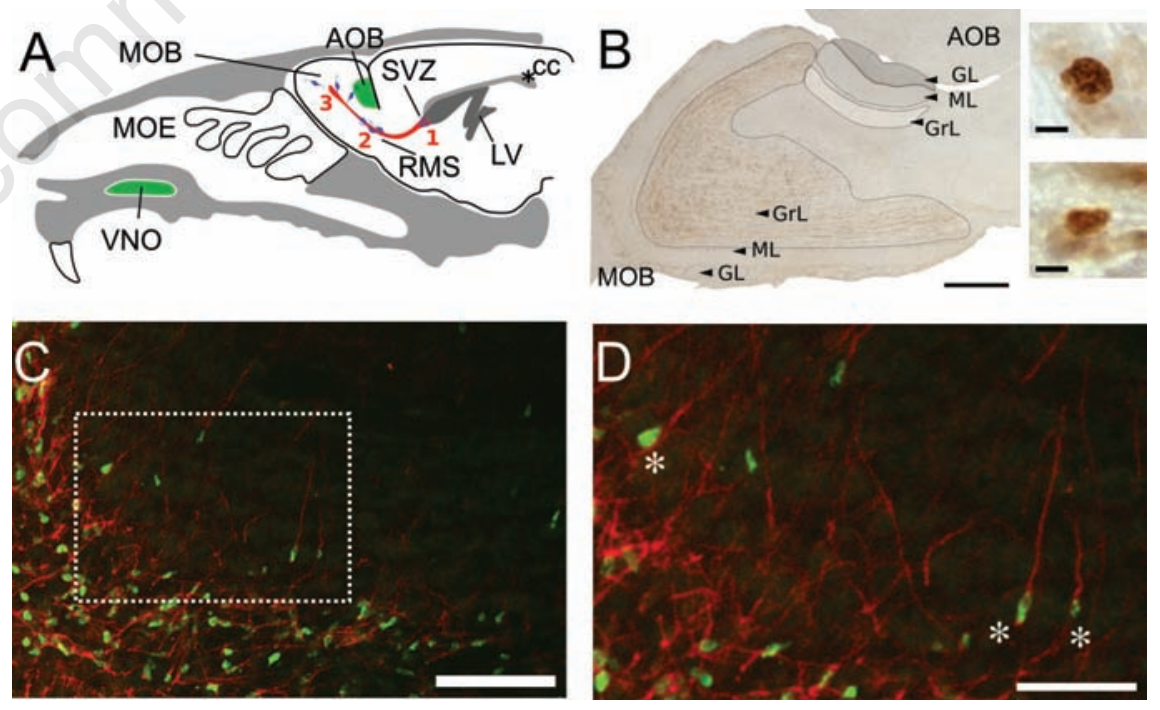

Figure 4. Neurogenesis in the main and accessory olfactory bulb. A) Schematic representation of the SVZ neurogenic niche showing the maturation steps of OB newborn cells: 1) proliferation, 2) migration through the rostral migratory stream (RMS), 3) radial migration and differentiation in the $\mathrm{AOB}$ and $\mathrm{MOB}$ (MOE, main olfactory epithelium; VNO, vomeronasal organ; LV, lateral ventricle; cc, corpus callosum). B) Parasagittal tissue slice showing BrdU labelling in the MOB and AOB cellular layers (lined in gray lines; GrL, granular layer; ML, mitral cell layer; GL, glomerular layer; scale bar: $200 \mu \mathrm{m}$ ). In the high magnification panels on the right AOB newborn cells are shown in detail (Scale bar: $5 \mu \mathrm{m}$ ). CD) Doublecortin/BrdU double-staining in the AOB showing immature neuroblasts integrating into the AOB GrL (asterisks in the right panel; Scale bar: $100 \mu \mathrm{m}$ left, $50 \mu \mathrm{m}$ right). 
The persistence of high levels of neuron production throughout adulthood and its conservation in several vertebrate species suggests that this process has fundamental biological significance. If in the hippocampus a strict correlation between adult neurogenesis and learning/memory has been described, ${ }^{41-46}$ the role played by newly-generated neurons in the olfactory pathway remains at present largely obscure. Moreover, their occurrence in both the main and the accessory $\mathrm{OB}$ (Figure $4 \mathrm{C}$ MOB, AOB), gives rise to speculations concerning the role of these new neurons in the modulation of different olfactory behavioral responses elicited by biologically relevant cues (such as semiochemicals and social odours) in the two sub-regions. ${ }^{47-50}$

\section{Neurogenesis in the accessory olfactory bulb}

On the medial-dorsal aspect of the $\mathrm{OB}$, a segregated portion of olfactory glomeruli receives the axons of the vomeronasal (VN) sensory neurons (Figure 4A; VNSNs). This region, namely the accessory $\mathrm{OB}(\mathrm{AOB})$, is dedicated to elaborate informations conveyed by vomeronasal sensory inputs, which are further sent by projection neurons (large principal cells, LPCs) to regions of the limbic system and the hypothalamus (for a review concerning the VN system see Halpern and Matinez$\left.\operatorname{Marcos}^{51}\right)$. Differently from the MOB LPCs (mitral-tufted cells), AOB LPCs are arranged in a sparse pattern, and do not belong to the same morphological categorization. ${ }^{52-53}$ The VN afferent pathway is splitted in two segregated bundles characterized by axons of neurons expressing two different G-protein coupled receptor sub-types: one is located in the apical VNO and carries the protein $\mathrm{Gi}_{\alpha}$, another is located in the basal part and is tagged by the presence of $\mathrm{Go}_{\alpha}$ (Figure 5A). ${ }^{54,55}$ The axons of apical and basal VNSNs coalesce separately to reach, respectively, the anterior and posterior glomeruli of the AOB and are identifiable with the anti-Gi $\alpha$ and anti-Go ${ }_{\alpha}$ antibodies, respectively (Figure 5B). These two AOB sub-regions have been hypothesized to play different roles in the exteroceptive modulation of social behaviours. ${ }^{56,57}$ Notably, neurogenesis has been documented in both AOB subdivisions and in different rodent species. . $^{47,49,58,59}$

Importantly, a functional circumstantial evidence for a role of the newly formed neuronal population in the $\mathrm{AOB}$ comes from our previous studies demonstrating a sexual dimorphism in the anterior AOB of the rat, with males showing a larger number of BrdU-positive nuclei than females. ${ }^{60}$ Moreover, among male rats the number of BrdU-positive cells, as well as their density, was higher in the anterior AOB region. Similarly, in the CD1 mouse strain more newborn cells are concentrated in the anterior portion of the $\mathrm{AOB}$, but this occurs in similar extent in both genders, ${ }^{49}$ while in C57BL/6J mice this anterior-posterior gradient is absent but males have more cells in the posterior AOB in comparison to females ${ }^{61}$ From a functional point of view, these results suggest the presence of a gender-related dimorphism potentially due to an organizational effect of sexual steroids, which is known to act during development. ${ }^{62}$ Indeed, the presence of gonadal steroid receptors in AOB neurons has been already established through immunohistochemical detection, ${ }^{63}$ thus implying that the activity of both young and mature neurons may be modulated directly by circulating hormones. Moreover, the anterior-posterior neurogenic differences are intriguing since functional differences between anterior and posterior $\mathrm{AOB}$ are well documented in rodents and could be the basis of different adaptations of the VN system to distinct ecological contexts. ${ }^{64,65}$

Eventually, this differential turnover-rate along the anterior-posterior axis, supports the hypothesis of a functional role of neurogenesis in AOB-mediated elaboration of sensory inputs which may differ in the two genders.

Ultimately, the idea that adult neurogenesis in the $\mathrm{OB}$ differentially contributes to olfactory sub-regions involved in diverse functions is further sustained by phenotypic differences of $\mathrm{MOB}$ and $\mathrm{AOB}$ newborn interneurons. Indeed, AOB granule cells show a strong nNOS staining while periglomerular cells completely lack TH staining, ${ }^{49,63}$ contrarily to what is known for those in the MOB glomerular layer. These observations leave open the question whether different populations of SVZ progenitors committed to populate the two sub-regions do exist. Alternatively, different regulatory mechanisms could be responsible for the local phenotypical specification of immature neurons of the same lineage.

\section{From chemical neuroanatomy to function and viceversa}

In a recent study, we exploited different immunocytochemical approaches to prove that neuronal survival in the AOB is actively driven by the exposure of female mice to individual male odours. ${ }^{49}$

Briefly, BrdU has been administered before the exposure of postnatal day (p) 56 female mice to male soiled bedding material for 28 days. Sampling of BrdU labelled cells in both the AOB and MOB was performed at p84. After exposure to male odours, the amount of new neurons found in both the $\mathrm{AOB}$ subregions (anterior and posterior) of female mice is increased. ${ }^{49}$ This effect was observed in both peri-puberal and adult animals (4 and 8 weeks old). ${ }^{49}$ Importantly, this sensory trigger for $\mathrm{OB}$ neurogenesis seems to have a stronger impact on $\mathrm{AOB}$ neuronal integration, since it was not evident in the MOB. ${ }^{49}$ Accordingly, exposing female mice to male volatile odour stimuli, which eventually do not activate VNSNs,${ }^{66-70} \mathrm{did}$ not exert the same effect on AOB neurogenesis. This suggests that a correlation exists between neuronal survival in the AOB and VNO-driven sensory activity.

Thus, considering the knowledge of the well described behavioural responses mediated by the VN sensory pathway such as aggression, puberty onset, sexual attraction and individual discrimination, ${ }^{67,71-74}$ the analysis of cell renewal in this restricted OB sub-region appears promising to unravel the meaning of such structural remodelling in relation with these behavioural and neuroendocrine processes.

Another point of interest regarding this model resides in the cito-architecture of the AOB itself: its highly convergent neural connectivity ${ }^{53}$ allows a precise analysis on a single-cell scale, ${ }^{75}$ which is presumably much harder to be accomplished in the MOB where sensory signals are processed in a less stereotyped manner and by less specific labelled-

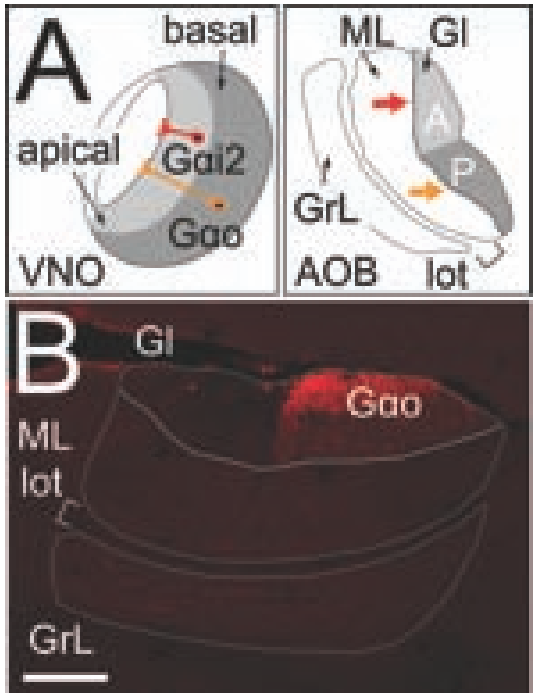

Figure 5. Distinct populations vomeronasal sensory neurons innervate the anterior and posterior AOB. A) Gai2 is expressed in apical vomeronasal sensory neurons projecting to the anterior AOB (A) while Goo labelling in the basal VNO sensory epithelium and posterior $A O B$ glomerular layer landmarks its posterior subdivision (P). B) Immunofluorescent labelling for Gao in the posterior $\mathrm{AOB}$ of $\mathrm{C} 57 \mathrm{BL} / 6 \mathrm{~J}$ mice. Scale bar: $200 \mu \mathrm{m}$. 
lines. The analysis can be addressed both on cell survival as well as on cell functional integration. The integration of exogenously labelled cells (e.g. BrdU-positive neurons and/or viral injections) can be imaged through detection of immediately early gene (IEG) expression. Recently, we have evaluated the percentage of c-Fos in AOB newborn granule cells of both female mice undergoing longterm exposure (28 days) to male soiled bedding material, after BrdU injection. After such chronic sensory stimulation, despite a generalized decrease in IEG expression levels in all mature granule (NeuN positive) neurons ${ }^{76}$ comparable levels are maintained in 28 days BrdU-expressing cells, implying that these cells maintain responsiveness to those sensory stimuli driving their integration. ${ }^{49}$ This is in agreement with recent studies showing that newborn cells are positively selected by experienced sensory stimuli, which eventually lead to the functional recruitment of the same cells in the related circuitry. ${ }^{43,77}$

Moving from neuronal integration analysis to the wider level of morpho-functional assessment of the role of the AOB subregions in modulating complex behavioural responses, further insights can be obtained by defining the sensory contexts in which newborn neurons find a niche to survive. Indeed, if we consider the effects of pheromonal sensory activity on neuronal survival in the two subregions, after exposure to both male and female pheromones, the amount of new neurons found in the anterior sub-region of the $\mathrm{AOB}$ is higher only in females after exposure to male pheromones, while it does not change in males (Oboti et al., unpublished data). These results are in agreement with the observation that the anterior $\mathrm{AOB}$ of adult females strongly respond to gender related odours. ${ }^{78,79}$ Considering that sexual pheromones are important primers on female development and reproductive behaviour, these findings suggest an active involvement of $\mathrm{AOB}$ postnatal/adult neurogenesis in pheromonal sensory processing in this gender and confirm the reliance of this form of $\mathrm{OB}$ plasticity to changing sensory demands. Alternatively, given the above mentioned presence of steroid hormone receptors in the $\mathrm{AOB}$, the modulation of $\mathrm{AOB}$ neurogenesis by male odour exposure could be an hormonal mediated side-effect without any specific adaptive value: the change in circulating hormone concentrations, much stronger in females than in males, could exert neuroprotective effects on integrating newborn bulbar interneurons as it has been shown in both periphera ${ }^{80,81}$ and central nervous system in either normal ${ }^{82}$ or injured conditions..$^{83,84}$

Now we have more immunohistochemical tools to visualize the functional activity of newborn neurons as they integrate into the differ- ent OB sub-regions (arc, egrl, c-jun, AP-1, zif268), and thus to clarify these issues. These approaches, although indirect and with some caveats, have the advantage to be less invasive than in vivo cell recording through electrode implantation and do not require elaborate $e x$ vivo tissue preparations.

\section{Conclusions}

Nowadays, it is known that both olfactory sub-systems, the main and accessory epithelia and bulbs are considered to have synergic roles in the sense of smell, and in parallel, both are subjected to life-long neurogenesis. In the future further analysis will clarify the dual role of this neuronal plasticity, both at the periphery or at the level of the $\mathrm{AOB}$ and $\mathrm{MOB}$, in the olfactory sensory coding. To this aim, ad hoc manipulations of the olfactory environment and/or olfactory sensory epithelia will be necessary to evaluate the differential impact of interneuronal recycling in the olfactory relays on different functional aspects of this chemical sense. Moreover, since early studies conceived in a more ethological perspective have left us a rich bulk of reports concerning the roles of the $\mathrm{MOB}$ and $\mathrm{AOB}$ in several behavioural and neuroendocrine contexts, now it is time to exploit this knowledge and look back to the anatomical and histological evidence of enduring plasticity in the primary olfactory regions.

This integrated approach could give a renewed and worthy meaning to all the efforts dedicated to the anatomical and morphological description of olfaction.

\section{References}

1. Tobet SA, Schwarting GA. Minireview: recent progress in gonadotropin-releasing hormone neuronal migration. Endocrinology 2006;147:1159-65.

2. Willhite DC, Nguyen KT, Masurkar AV, Greer CA, Shepherd GM, Chen WR. Viral tracing identifies distributed columnar organization in the olfactory bulb. Proc Natl Acad Sci USA 2006;33:12592-7.

3. Rochefort C, Gheusi G, Vincent JD, Lledo PM. Enriched odor exposure increases the number of newborn neurons in the adult olfactory bulb and improves odor memory. J Neurosci 2002;22:2679-89.

4. Alonso M, Viollet C, Gabellec MM, MeasYedid V, Olivo-Marin JC, Lledo PM. Olfactory discrimination learning increases the survival of adult-born neurons in the olfactory bulb. J Neurosci 2006;26: 10508-13.
5. Nissant A, Bardy C, Katagiri H, Murray K, Lledo PM. Adult neurogenesis promotes synaptic plasticity in the olfactory bulb. Nat Neurosci 2009;12:728-30.

6. Barber PC. Neurogenesis and regeneration in the primary olfactory pathway of mammals. Bibl Anat 1982;23:12-25.

7. Herzog C, Otto T. Regeneration of olfactory receptor neurons following chemical lesion: time course and enhancement with growth factor administration. Brain Res 1999;849:155-61.

8. Matsuoka M, Osada T, Yoshida-Matsuoka J, Ikai A, Ichikawa M, Norita M, Costanzo RM. A comparative immunocytochemical study of development and regeneration of chemosensory neurons in the rat vomeronasal system. Brain Res 2002; 946:52-63.

9. Petreanu L, Alvarez-Buylla A. Maturation and death of adult-born olfactory bulb granule neurons: role of olfaction. J Neurosci 2002;22:6106-13.

10. Beites CL, Kawauchi S, Crocker CE, Calof AL. Identification and molecular regulation of neural stem cells in the olfactory epithelium. Exp Cell Res 2005;306:309-16.

11. Liu H, Guthrie KM. Neuronal replacement in the injured olfactory bulb. Experimental Neurology 2011;228:270-282.

12. Murdoch B, Roskams AJ. Olfactory epithelium progenitors: insights from transgenic mice and in vitro biology. $\mathrm{J}$ Mol Histol 2007;38:581-99.

13. Graziadei PPC and Monti Graziadei GA, Continuous nerve cell renewal in the olfactory system. Pages 55-83 in: Jacobson M (ed.) Handbook of Sensory Physiology. Volume IX: Development of Sensory Systems. Springer-Verlag, New York, USA, 1978.

14. Schwartz Levey M, Chikaraishi DM, Kauer JS. Characterization of potential precursor populations in the mouse olfactory epithelium using immunocytochemistry and autoradiography. J Neurosci 1991;11:355664.

15. Caggiano M, Kauer JS, Hunter DD. Globose basal cells are neuronal progenitors in the olfactory epithelium: a lineage analysis using a replication-incompetent retrovirus. Neuron 1994;13:339-52.

16. Frontiers in Neurogenesis 2011. Research topic. Cellular Imaging and Emerging Technologies for Adult Neurogenesis Research. Hosted by: S. De Marchis and A.C. Puche.

17. Farbman AI. Olfactory neurogenesis: genetic or environmental controls? Trends Neurosci 1990;13:362-5.

18. Margolis FL. Solid-phase radioimmune assay. Using $3 \mathrm{H}$-labeled antigen for the mouse olfactory bulb specific protein. Anal Biochem 1972;50:602-7. 
19. Gong Q, Shipley MT. Expression of extracellular matrix molecules and cell surface molecules in the olfactory nerve pathway during early development. J Comp Neurol 1966;366:1-14.

20. Bonfanti L, Peretto P, De Marchis S, Fasolo A. Carnosine-related dipeptides in the mammalian brain. Prog Neurobiol 1999; 59:333-53.

21. Rochel S, Margolis FL. Carnosine release from olfactory bulb synaptosomes is calcium-dependent and depolarization-stimulated. J Neurochem 1982;38:1505-14.

22. Graziadei PP, Monti Graziadei GA Neurogenesis and plasticity of the olfactory sensory neurons. Ann NY Acad Sci 1985; 457:127-42.

23. Barber PC, Raisman G. Cell division in the vomeronasal organ of the adult mouse. Brain Res 1978;141:57-66.

24. Samanen DW, Forbes WB. Replication and differentiation of olfactory receptor neurons following axotomy in the adult hamster: a morphometric analysis of postnatal neurogenesis. J Comp Neurol 1984;225: 201-11.

25. Costanzo RM. Regeneration of olfactory receptor cells. In: Regeneration of Vertebrate Sensory Receptor Cells. Ciba Foundation Symposium; 1991 discussion 243-248. 160:223-242. Wiley, Chichester, UK, 1991.

26. Kaba H, Rosser AE, Keverne EB. Hormonal enhancement of neurogenesis and its relationship to the duration of olfactory memory. Neuroscience 1988;24:93-8.

27. Mombaerts P. Molecular biology of odorant receptors in vertebrates. Annu Rev Neurosci 1999;22:487-509.

28. Potter SM, Zheng C, Koos DS, Feinstein P, Fraser SE, Mombaerts P. Structure and emergence of specific olfactory glomeruli in the mouse. J Neurosci 2001;21:9713-23.

29. Bozza T, Feinstein P, Zheng C, Mombaerts P. Odorant receptor expression defines functional units in the mouse olfactory system. J Neurosci 2002;22:3033-43.

30. Bonfanti L. PSA-NCAM in mammalian structural plasticity and neurogenesis. Prog Neurobiol. 2006;80:129-64.

31. Altman J, Das GD. Autoradiographic and histological evidence of postnatal hippocampal neurogenesis in rats. $\mathrm{J}$ Comp Neurol 1965;124:319-35.

32. Altman J. Autoradiographic and histological studies of postnatal neurogenesis IV. Cell proliferation and migration in the anterior forebrain, with special reference to persisting neurogenesis in the olfactory bulb. J Comp Neurol 1969;137:433-58.

33. Alvarez-Buylla A, Kirn JR. Birth, migration, incorporation, and death of vocal control neurons in adult songbirds. J. Neurobiol
1997;33:585-601.

34. Kirn JR, Fishman Y, Sasportas K, AlvarezBuylla A, Nottebohm F. Fate of new neurons in adult canary High Vocal Center during the first 30 days after their formation. J Comp Neurol 1999;411:487-94.

35. Rakic P. Limits of neurogenesis in primates. Science 1985;4690:1054-6.

36. Lois C, Alvarez-Buylla A. Long-distance neuronal migration in the adult mammalian brain. Science 1994;5162:1145-8.

37. Luskin MB. Restricted proliferation and migration of postnatally generated neurons derived from the forebrain subventricular zone. Neuron 1993;11:173-89.

38. Reynolds BA, Weiss S. Generation of neurons and astrocytes from isolated cells of the adult mammalian central nervous system. Science 1992;255:1707-10.

39. Peretto P, Merighi A, Fasolo A, Bonfanti L. Glial tubes in the rostral migratory stream of the adult rat. Brain Res Bull 1997;42:921.

40. Peretto P, Giachino C, Aimar P, Fasolo A, Bonfanti L. Chain formation and glial tube assembly in the shift from neonatal to adult subventricular zone of the rodent forebrain. J Comp Neurol 2005;487:407-27.

41. Kempermann G, Kuhn HG, Gage FH. Experience-induced neurogenesis in the senescent dentate gyrus. J Neurosci 1998;18:3206-12.

42. Gould E, Tanapat P, Hastings NB, Shors TJ. Neurogenesis in adulthood: a possible role in learning. Trends Cogn Sci 1999;3:18692.

43. Kee N, Teixeira CM, Wang AH, Frankland PW. Preferential incorporation of adultgenerated granule cells into spatial memory networks in the dentate gyrus. Nat Neurosci 2007;10:355-62.

44. Waddell J, Shors TJ. Neurogenesis, learning and associative strength. Eur $\mathrm{J}$ Neurosci 2008;27:3020-8.

45. Kitamura T, Saitoh Y, Takashima N, Murayama A, Niibori Y, Ageta $\mathrm{H}$, et al. Adult neurogenesis modulates the hippocampus-dependent period of associative fear memory. Cell 2009;139:814-27.

46. Aimone JB, Deng W, Gage FH. Adult neurogenesis: integrating theories and separating functions. Trends Cogn Sci 2010; 14:325-37.

47. Bonfanti L, Peretto P, Merighi A, Fasolo A. Newly-generated cells from the rostral migratory stream in the accessory olfactory bulb of the adult rat. Neuroscience 1997;81:489-502.

48. Hendrickson RC, Krauthamer S, Essenberg JM, Holy TE. Inhibition shapes sex selectivity in the mouse accessory olfactory bulb. J Neurosci 2008;28:1252334.
49. Oboti L, Savalli G, Giachino C, De Marchis S, Panzica GC, Fasolo A, et al. Integration and sensory experience-dependent survival of newly-generated neurons in the accessory olfactory bulb of female mice. Eur J Neurosci 2009;29:679-92.

50. Gheusi G, Ortega-Perez I, Murray K, Lledo PM. A niche for adult neurogenesis in social behavior. Behav Brain Res 2009; 200:315-22.

51. Halpern M, Martínez-Marcos A. Structure and function of the vomeronasal system: an update. Prog Neurobiol 2003;70:245318.

52. Lohman AHM. The anterior olfactory lobe of the guinea pig. A descriptive and experimental anatomical study. Acta Anat 1963; 53:1-109.

53. Larriva-Sahd. The Accessory Olfactory Bulb in the Adult Rat: A Cytological Study of Its Cell Types, Neuropil, Neuronal Modules, and Interactions with the Main Olfactory System. J Comp Neurol 2008; 510:309-50.

54. Berghard, A, Buck, L. B. Sensory transduction in vomeronasal neurons: evidence for G 0, G i2, G, and adenylyl cyclase II as major components of a pheromone signaling cascade. J Neurosci 1996;16:909-18.

55. Jia, C, Halpern, M. Subclasses of vomeronasal receptor neurons: differential expression of G proteins (Gi 2 and Go) and segregated projections to the accessory olfactory bulb. Brain Res 1996;719:117-28.

56. Dudley CA, Moss RL. Activation of an anatomically distinct subpopulation of accessory olfactory bulb neurons by chemosensory stimulation. Neuroscience 1999;91:1549-56.

57. Kumar A, Dudley CA, Moss RL. Functional dichotomy within the vomeronasal system: distinct zones of neuronal activity in the accessory olfactory bulb correlate with sexspecific behaviors. J Neurosci 1999;19: RC32.

58. Bayer SA. 3H-thymidine-radiographic studies of neurogenesis in the rat olfactory bulb. Exp Brain Res 1983;50:329-40.

59. Martínez-Marcos A, Ubeda-Bañón I, Halpern M. Cell migration to the anterior and posterior divisions of the granule cell layer of the accessory olfactory bulb of adult opossums. Brain Res Dev Brain Res 2001;127:95-8.

60. Peretto P, Giachino C, Panzica GC, Fasolo A. Sexually dimorphic neurogenesis is topographically matched with the anterior accessory olfactory bulb of the adult rat. Cell Tissue Res 2001;306:385-9.

61. Nunez-Parra A, Pugh V, Araneda RC. Regulation of adult neurogenesis by behavior and age in the accessory olfactory bulb. Mol Cell Neurosci 2011;47:274-85. 
62. Valencia A, Collado P, Calés JM, Segovia S, Pérez Laso C, Rodríguez Zafra M, et al. Postnatal administration of dihydrotestosterone to the male rat abolishes sexual dimorphism in the accessory olfactory bulb: a volumetric study. Brain Res Dev Brain Res 1992;68:132-5.

63. Shipley, M.T., Ennis, M, Puche, A.C. The olfactory system. Pages 921-962 in: Paxinos G (ed.) The rat nervous system, 3rd edition. Elsevier, New York, USA, 2004.

64. Suárez R, Santibáñez R, Parra D, Coppi AA, Abrahão LM, Sasahara TH, et al. Shared and differential traits in the accessory olfactory bulb of caviomorph rodents with particular reference to the semiaquatic capybara. J Anat 2011;218:558-65.

65. Schneider NY. The development of the olfactory organs in newly hatched monotremes and neonate marsupials. J Anat 2011;219:229-42.

66. Moncho-Bogani J, Lanuza E, Hernández A, Novejarque A, Martínez-García F. Attractive properties of sexual pheromones in mice: innate or learned? Physiol Behav 2002;77:167-76.

67. Moncho-Bogani J, Martinez-Garcia F, Novejarque A, Lanuza E. Attraction to sexual pheromones and associated odorants in female mice involves activation of the reward system and basolateral amygdala. Eur J Neurosci 2005;21:2186-98.

68. Leinders-Zufall T, Lane AP, Puche AC, Ma W, Novotny MV, Shipley MT, et al. Ultrasensitive pheromone detection by mammalian vomeronasal neurons. Nature 2000;405:792-6.

69. Trinh K, Storm DR. Vomeronasal organ detects odorants in absence of signaling through main olfactory epithelium. Nat Neurosci 2003;6:519-25.

70. Muroi Y, Ishii T, Komori S, Nishimura M. A competitive effect of androgen signaling on male mouse attraction to volatile female mouse odors. Physiol Behav 2006; 87:199-205.

71. Maruniak JA, Wysocki CJ, Taylor JA. Mediation of male mouse urine marking and aggression by the vomeronasal organ. Physiol Behav 1986;37:655-7.

72. Lomas DE, Keverne EB. Role of the vomeronasal organ and prolactin in the acceleration of puberty in female mice. $J$ Reprod Fertil 1982;66:101-7.

73. Ramm SA, Cheetham SA, Hurst JL. Encoding choosiness: female attraction requires prior physical contact with individual male scents in mice. Proc Biol Sci 2008;275:1727-35.

74. Wyatt, T. Pheromones and animal behaviour: communication by smell and taste. Cambridge University Press, Cambridge, UK, 2003.

75. Luo M, Katz LC. Encoding pheromonal signals in the mammalian vomeronasal system. Curr Opin Neurobiol 2004;14:428-34.

76. Buonviso N, Chaput M. Olfactory experience decreases responsiveness of the olfactory bulb in the adult rat. Neuroscience 2000;95:325-32.

77. Magavi SS, Mitchell BD, Szentirmai 0, Carter BS, Macklis JD. Adult-born and preexisting olfactory granule neurons undergo distinct experience-dependent modifications of their olfactory responses in vivo. J Neurosci 2005;25:10729-39.

78. Halem HA, Baum MJ, Cherry JA. Sex difference and steroid modulation of pheromone-induced immediate early genes in the two zones of the mouse accessory olfactory system. J Neurosci 2001;21:2474-80.

79. Halem HA, Cherry JA, Baum MJ. Central forebrain Fos responses to familiar male odours are attenuated in recently mated female mice. Eur J Neurosci 2001;13:38999.

80. Samantaray S, Sribnick EA, Das A, Thakore NP, Matzelle D, Yu SP, et al. Neuroprotective efficacy of estrogen in experimental spinal cord injury in rats. Ann N Y Acad Sci 2010;1199:90-4.

81. Tehranipour M, Moghimi A. Neuroprotective effects of testosterone on regenerating spinal cord motoneurons in rats. $\mathrm{J}$ Mot Behav 2010;42:151-5.

82. Zhang Z, Yang R, Zhou R, Li L, Sokabe M, Chen $L$. Progesterone promotes the survival of newborn neurons in the dentate gyrus of adult male mice. Hippocampus 2010;20:402-12.

83. Brown CM, Suzuki S, Jelks KA, Wise PM. Estradiol is a potent protective, restorative, and trophic factor after brain injury. Semin Reprod Med 2009;27:240-9.

84. Zhang Z, Yang R, Cai W, Bai Y, Sokabe M, Chen L. Treatment with progesterone after focal cerebral ischemia suppresses proliferation of progenitor cells but enhances survival of newborn neurons in adult male mice. Neuropharmacology 2010;58:930-9.

85. Oboti L, Peretto P, De Marchis S, Fasolo A. From chemical neuroanatomy to functional understanding of the olfactory system. Eur J Histochem 2011;55(suppl. 1):1. 